\title{
Interleukin-8 (CXCL8) stimulates trophoblast cell migration and invasion by increasing levels of matrix metalloproteinase (MMP)2 and MMP9 and integrins $\alpha_{5}$ and $\beta_{1}$
}

\author{
Milica Jovanović, Ivana Stefanoska, Ljiljana Radojčić ${ }^{1}$ and Ljiljana Vićovac \\ Institute for the Application of Nuclear Energy, INEP, University of Belgrade, Banatska 31 b, 11080 Belgrade, Serbia \\ and ${ }^{1}$ Military Medical Academy, 11000 Belgrade, Serbia \\ Correspondence should be addressed to L Vićovac; Email: vicovac@inep.co.rs
}

\begin{abstract}
Interleukin-8 (IL8/CXCL8) is present in decidua and trophoblast, which also expresses the IL8 receptors, CXCR1 and CXCR2. IL8 was shown to stimulate trophoblast migration. Matrix metalloproteinase (MMP)2, MMP9, and integrins $\alpha_{5} \beta_{1}$ and $\alpha_{1} \beta_{1}$ were found to play important roles in trophoblast invasion. We hypothesized that IL8 would increase this cell migration and invasion by HTR-8/SVneo cells through the activity of MMPs and integrins. Isolated first trimester of pregnancy cytotrophoblast (CT) and HTR-8/SVneo cell line were used. Migration was studied by monolayer wounding test, and invasion by Matrigel invasion test. The effects of IL8 on MMPs and integrin subunit expression were determined in HTR-8/SVneo cells by gelatin zymography and western blot respectively. The results that were obtained showed that exogenous IL8 stimulated HTR-8/SVneo cell migration and invasion. MMP2 and MMP9 levels were stimulated to $182 \%(P<0.01)$ and $134 \%(P<0.01)$ respectively. Integrin $\alpha_{5}$ expression was increased to $119 \%(P<0.05)$ and integrin $\beta_{1}$ expression to $173 \%(P<0.001)$ of the control values. The data that were obtained show for the first time the sensitivity of the HTR-8/SVneo cells, in addition to isolated first trimester CT, to IL8. Exogenous IL8/CXCL8 increased trophoblast cell migration and invasion, which may be partly attributable to stimulation of MMP2 and MMP9 levels and an increase in integrins. HTR-8/SVneo cell viability and proliferation were also increased.
\end{abstract}

Reproduction (2010) 139 789-798

\section{Introduction}

Extravillous trophoblast (EVT) cells are specific cells of the placenta that can invade into the decidual stroma and spiral arteries of the uterus. Invasion of the uterine decidua and inner third of the myometrium by EVT cells is a step that is crucial for establishing a successful pregnancy (Pijnenborg et al. 1983). During this process, trophoblast cells undergo a change in integrin phenotype acquiring integrins $\alpha_{5} \beta_{1}$ and $\alpha_{1} \beta_{1}$ (Damsky et al. 1992). The invasive properties of the EVT are linked to their ability to degrade the extracellular matrix (Fisher et al. 1985) by secreting proteolytic enzymes (reviewed by Cohen et al. (2006)). Matrix metalloproteinases-2 and -9 (MMP2 and MMP9) are particularly relevant for this process (Lala \& Graham 1990, Librach et al. 1991). Various autocrine and paracrine factors have been suggested to modulate trophoblast function (reviewed by Salamonsen et al. (2007)). Many cytokines are produced by both trophoblast and diverse decidual cell types, and some, such as tumor necrosis factor- $\alpha$ (TNF; Bauer et al. 2004), interleukin-1 (IL1; Librach et al. 1994), interferon- $\gamma$ (Lash et al. 2006), leukemia inhibitory factor (LIF;
Poehlmann et al. 2005), IL6 (Jovanović \& Vićovac 2009), and transforming growth factor- $\beta$ (TGFB; Caniggia et al. 1999, Lash et al. 2005), are implicated in the regulation of trophoblast invasion.

In the first trimester of pregnancy, when trophoblast invasion is most extensive, decidualized endometrium is composed of different cytokine-producing immune and non-immune cell types (Starkey et al. 1988). One of these cytokines is IL8 (CXCL8), a proinflammatory molecule belonging to the CXC chemokine subfamily. Within the uterus, the presence of IL8 has been documented in endometrial (Arici et al. 1993) and decidual (Saito et al. 1994) epithelial and stromal cells, decidual natural killer (NK) cells (Hanna et al. 2006), decidual macrophages exposed to trophoblast (Fest et al. 2007), and decidual CD8 ${ }^{+} \mathrm{T}$ lymphocytes (Scaife et al. 2006). This $8 \mathrm{kDa}$ non-glycosylated protein is produced by many cell types, including monocytes, lymphocytes, granulocytes, fibroblasts, endothelial cells, bronchial epithelial cells, keratinocytes, hepatocytes, mesangial cells, and chondrocytes (reviewed by lizasa \& Matsushima (2000)). IL8 is a potent neutrophil chemoattractant (Harada et al. 1994) and stimulator of neutrophil 
transendothelial migration (Huber et al. 1991). It also induces angiogenesis (Koch et al. 1992) and inhibits proliferation of myeloid progenitor cells (Sanchez et al. 1998). Trophoblast and placental macrophages constitutively produce IL8, the concentration of which is highest at term (Shimoya et al. 1992). IL8 mRNA and protein were also localized in cytotrophoblast (CT), syncytiotrophoblast, and Hofbauer cells of the placenta (Saito et al. 1994). IL8 binds to two receptor types, CXCR1 and CXCR2. The former has been demonstrated on EVT (Hanna et al. 2006), isolated CT, and the BeWo cell line (Tsui et al. 2004). Villous cytotrophoblast (vCT) cells were shown to express mRNA for both CXCR1 and CXCR2 (Hirota et al. 2009). IL8 from decidual NK cells (Hanna et al. 2006) and endometrial epithelial cells (Hirota et al. 2009) was found to promote EVT migration, and to stimulate survival of $\mathrm{vCT}$ cells in vitro (Hirota et al. 2009). The aim of this study was to determine the suitability of the HTR-8/SVneo cell line, derived from the first trimester EVT, as a model for IL8-induced effects on the invasive trophoblast. We hypothesized that IL8 would 1) increase cell migration and invasion of HTR-8/ SVneo cells, 2) increase levels of MMP2 and MMP9, as well as the expression of integrins, and 3) increase cell proliferation and/or survival.

\section{Results}

Even though IL8 was reported to influence trophoblast cell migration (Hanna et al. 2006), its effect on the human trophoblast has not been studied using the HTR-8/SVneo cell line. Earlier studies showed that HTR-8/SVneo immortalized first trimester of pregnancy trophoblast cells produced IL8 at concentrations of $0.06-1 \mathrm{ng} / \mathrm{ml}$ in $24 \mathrm{~h}$ depending on culture conditions (Svinarich et al. 1996, Chou et al. 2006). Here, we confirmed that this cell line produces IL8, as weak to moderate cytoplasmic staining was detected by immunocytochemistry in both CT (identified by CK7 staining, Fig. 1A) and HTR-8/SVneo cells (Fig. 1B). Isolated EVT was found to express CXCR1 protein (Hanna et al. 2006). In addition to isolated trophoblast (Fig. 1C), we detected the CXCR1 in HTR-8/SVneo cells as well (Fig. 1D). The same receptor was detected on both cell types by flow cytometry (Fig. 2). Flow cytometric analysis provided data that $90 \%$ of isolated CT (Fig. 2A) and $99 \%$ of HTR-8/SVneo cells (Fig. 2B) were positive.

Under some conditions, the invasive trophoblast in vivo may be exposed to considerable amounts of IL8 from one or more cell types that produce it within the decidua. Therefore, we wished to establish whether additional exogenous IL8 may influence trophoblast invasion and migration. The potentially effective concentrations of IL8 for HTR-8/SVneo cells were in the lower nanogram range of IL8 $(0.5-10 \mathrm{ng} / \mathrm{ml})$ in cell migration tests (Fig. 3) at 3 and $24 \mathrm{~h}$ of culture. The data had a bell-shaped curve, with all tested concentrations $(0.5,1,5$, and $10 \mathrm{ng} / \mathrm{ml})$ having stimulatory effects on
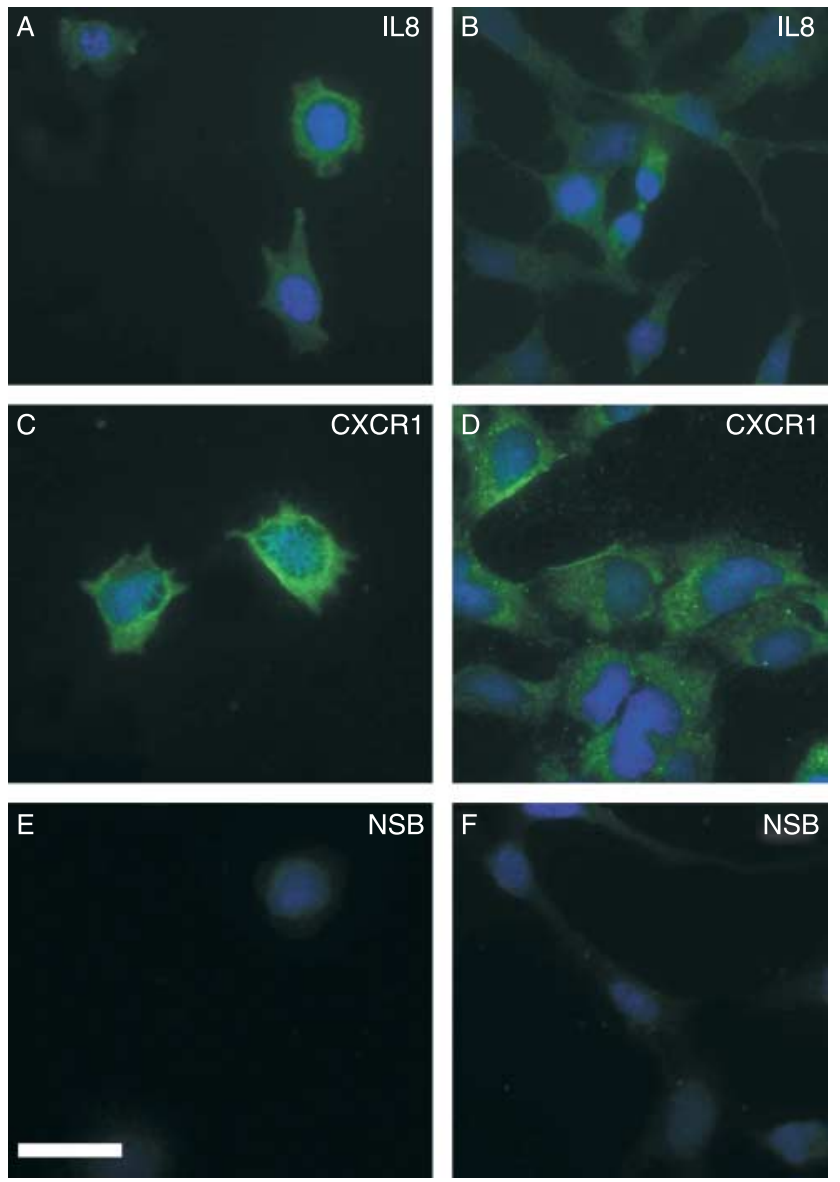

Figure 1 Expression of IL8 and IL8 receptor CXCR1 by trophoblast cells. Immunocytochemical detection of IL8 (A and B) and CXCR1 (C and D) in cytotrophoblast (A, C, and E) and HTR-8/SVneo cells

(B, D, and F). Both cell types are stained for IL8 (fluorescence in A and B) and CXCR1 (fluorescence in C and D). Non-specific staining (NSB, isotype-matched control $\operatorname{lgG}, \mathrm{E}$ and $\mathrm{F}$ ), and nuclei stained with DAPI (blue), scale bar $=20 \mu \mathrm{m}$.

HTR-8/SVneo cell migration (124, 166, 167, and 131\% of the control values respectively) after $3 \mathrm{~h}$ of culture (significant at $P<0.05, P<0.001, P<0.001$, and $P<0.05$ respectively; Fig. 3A). After $24 \mathrm{~h}$ of culture, the effects of IL8 were less pronounced, but were stimulatory for 1 and $5 \mathrm{ng} / \mathrm{ml}(127 \%, P<0.001$, and $125 \%, P<0.001$, of the control values respectively; Fig. $3 \mathrm{~B}$ ). The time course of this effect for a representative field is shown in the photomicrograph in Fig. 3C.

In migration and invasion experiments, functionblocking anti-IL8 or non-immune immunoglobulins were added to culture media in order to assess the influence of endogenous IL8 on cell migration and invasion. Addition of function-blocking anti-IL8 antibodies at $1 \mu \mathrm{g} / \mathrm{ml}$ had no effect on cell migration after $3 \mathrm{~h}$ of culture (Fig. 3A), but after $24 \mathrm{~h}$ of culture, anti-IL8 antibodies decreased cell migration to $90 \%$ $(P<0.01)$ of the control (Fig. 3B), while non-immune IgG at $1 \mu \mathrm{g} / \mathrm{ml}$ had no effect on cell migration. The stimulation by exogenous IL8 at $5 \mathrm{ng} / \mathrm{ml}$ was decreased 


\section{CXCR1 expression}

A

CT

B

HTR-8/SVneo

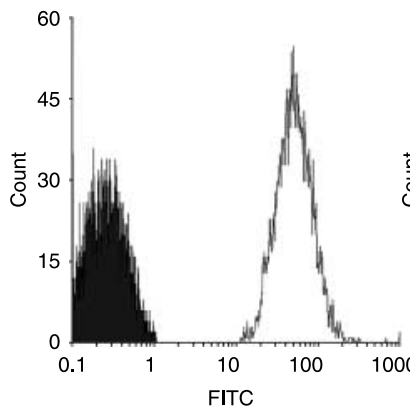

Fluorescence

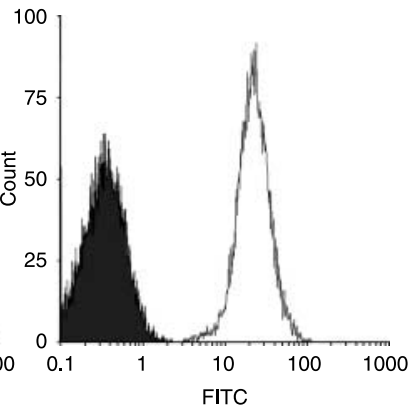

Fluorescence
Figure 2 Expression of CXCR1 in isolated cytotrophoblast (CT) (A) and HTR-8/SVneo cells (B) measured cytofluorometrically. The $x$-axis indicates fluorescence intensity measured on a $\log 10$ scale, and the $y$-axis indicates event counts on a linear scale. Specific staining is shown as white histograms, and non-specific staining (isotype-matched control $\lg \mathrm{G}$ ) as black histograms. A representative experiment of three for isolated CT is shown, and of five for HTR-8/SVneo cells is shown.

to values that were not significantly different from the control values when function-blocking anti-IL8 antibodies at $5 \mu \mathrm{g} / \mathrm{ml}$ were added (Fig. $3 \mathrm{~A}$ and B).

In the Matrigel invasion assay, IL8 at $5 \mathrm{ng} / \mathrm{ml}$ was found to increase invasion significantly both by freshly isolated CT (Fig. 4A) to $175 \%(P<0.01)$ of the control and by HTR-8/SVneo cells (Fig. 4B) to $150 \%$ of the control $(P<0.001)$. With function-blocking anti-IL8 antibodies $(1 \mu \mathrm{g} / \mathrm{ml})$, unstimulated HTR-8/SVneo cell invasion was $80 \%(P<0.05$; Fig. $4 \mathrm{~B})$ and isolated CT invasion was $90 \%$ of the control value, but this slight inhibition was not statistically significant. Non-immune IgG had no effect on cell invasion in either cell type. The addition of anti-IL8 at $5 \mu \mathrm{g} / \mathrm{ml}$ to the media with recombinant IL8 at $5 \mathrm{ng} / \mathrm{ml}$ decreased the invasion to values that were not significantly different from the control values (Fig. 4A and B).

To elucidate the potential effector molecules involved in IL8-induced cell migration and invasion, MMP2 and MMP9 gelatinase levels were studied using gelatin zymography. Densitometric analysis revealed that IL8 stimulated pro-MMP2 level to $182 \%$ of the control values (Fig. $5 \mathrm{~A}, P<0.01$ ) and pro-MMP9 level to $134 \%$ (Fig. 5B, $P<0.01$ ) of the control values respectively.

Integrin subunit $\alpha_{5}, \alpha_{1}$, and $\beta_{1}$ expression in HTR-8/ SVneo cells was examined by western blot analysis of lysates of cells treated with IL8. Densitometry showed specific bands of $\sim 150,130$, and $130 \mathrm{kDa}$ for integrins $\alpha_{5}, \beta_{1}$, and $\alpha_{1}$ respectively. The bands for $\alpha_{5}$ and $\beta_{1}$ integrin subunits were more intense in IL8-treated HTR-8/ SVneo cells. All intensities were normalized to actin band intensity, and were compared. Integrin subunits $\alpha_{5}$ and $\beta_{1}$ were increased to $119 \%$ (Fig. $6 \mathrm{~A}, P<0.05$ ) and $173 \%$ of the control values (Fig. $6 \mathrm{~B}, P<0.001$ ), while integrin $\alpha_{1}$ expression was not affected by IL8 (Fig. 6C).
The possibility that IL8 may influence trophoblast cell proliferation and survival was tested in the HTR-8/SVneo cell model. In the 3-(4,5-dimethylthiazol-2-yl)-2,5 diphenyltetrazolium bromide; thiazolyl blue (MTT) test, viable cell numbers detected in treated versus untreated cultures showed that IL8 $(5 \mathrm{ng} / \mathrm{ml})$ induced an increase to $112 \%$ of the control value $(P<0.001)$ after $24 \mathrm{~h}$ of culture and to $115 \%(P<0.001)$ after $48 \mathrm{~h}$ (Fig. $7 \mathrm{C})$.

A

HTR-8/SVneo cell migration
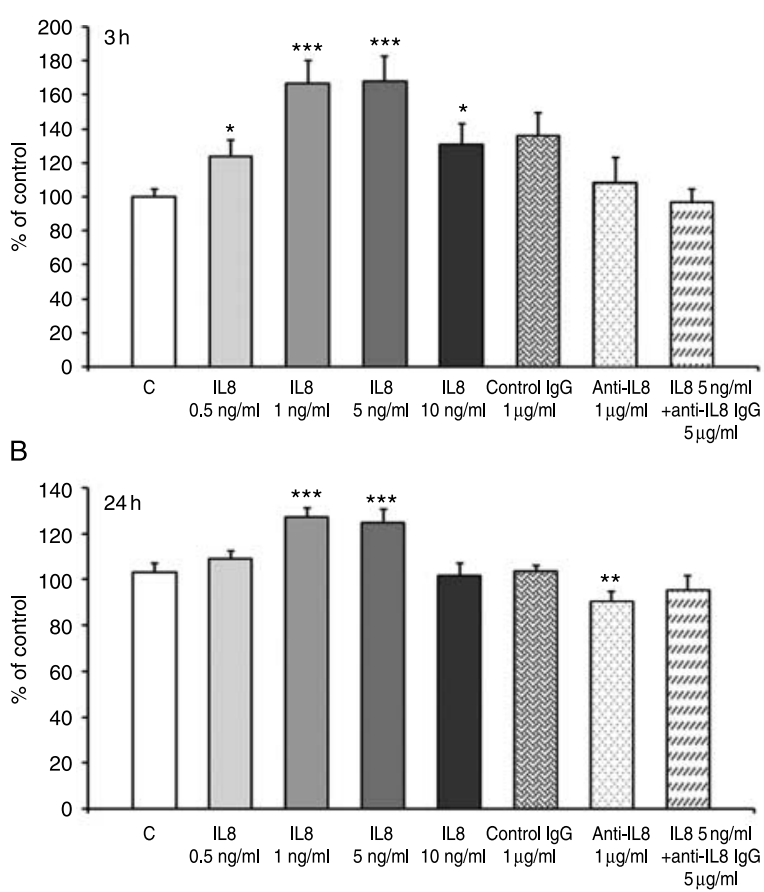

C

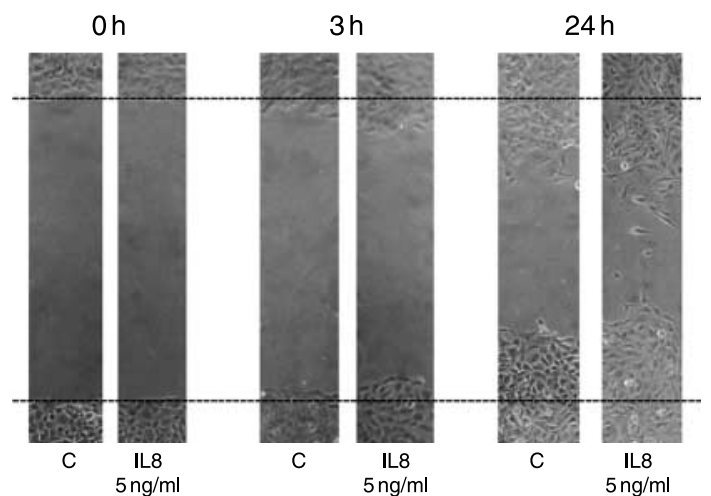

Figure 3 IL8 induced stimulation of HTR-8/SVneo cell migration. Time and concentration dependence of the IL8 effect on HTR-8/SVneo cell migration and neutralization of IL8 with specific function-blocking antibody. The effect of nanogram concentrations $(0.5,1,5$, and $10 \mathrm{ng} / \mathrm{ml}$ ) of IL8 and anti-IL8 antibody at 1 or $5 \mu \mathrm{g} / \mathrm{ml}$ after $3 \mathrm{~h} \mathrm{(A)} \mathrm{and}$ $24 \mathrm{~h}$ of culture (B). The distances were measured using an electronic grid $\left(0.1 \times 0.1 \mathrm{~mm}^{2}\right)$. Photomicrograph of cell migration after 0,3 , and $24 \mathrm{~h}$ for control and IL8-treated cells $(5 \mathrm{ng} / \mathrm{ml})$, a representative field (C). Data (from four experiments, two replicate wells, and three areas measured per well) are expressed as the percentage of the untreated control, with values given as mean \pm S.E.M., and statistical significance given as * for $P<0.05$; $*$ for $P<0.01$; and ${ }^{* * *}$ for $P<0.001$. 


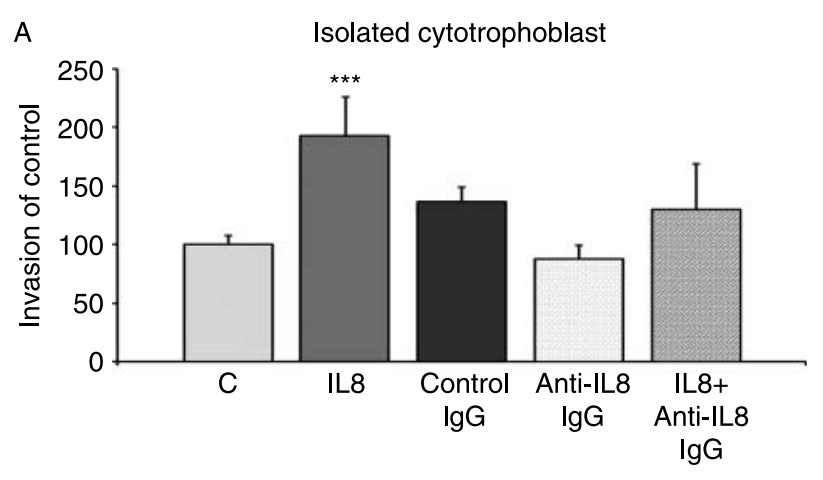

B

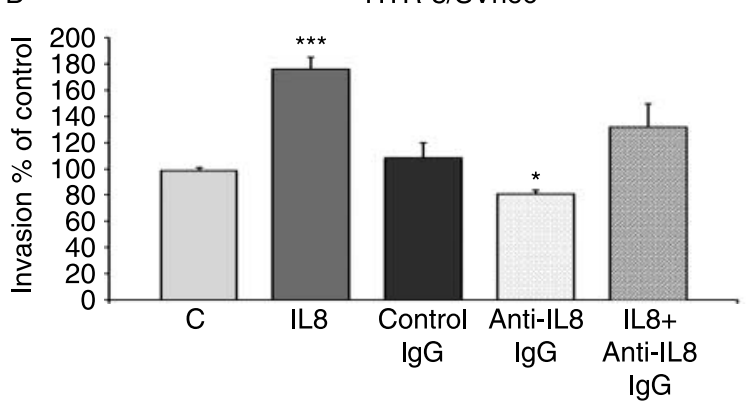

Figure 4 IL8 induced stimulation of trophoblast invasion. Effects of IL8 ( $5 \mathrm{ng} / \mathrm{ml})$, function-blocking anti-IL8 antibodies ( 1 or $5 \mu \mathrm{g} / \mathrm{ml})$, and non-immune $\operatorname{lgG}(1 \mu \mathrm{g} / \mathrm{ml})$ on cell invasion by (A) freshly isolated cytotrophoblast from the first trimester placenta and (B)

HTR-8/SVneo cell line. Cells on the underside of the filters and the pores occupied were counted after $20 \mathrm{~h}$ of culture for isolated cytotrophoblast and after $24 \mathrm{~h}$ for HTR-8/SVneo cells. The data are expressed as the percentage of the pores occupied in the control, with values given as mean \pm s.E.M. Differences were significant at $P<0.01$ for primary trophoblast (four experiments and two replicates) and at $P<0.001$ for HTR-8/SVneo cell invasion (six experiments and two replicates) treated with IL8. Treatment with anti-IL8 antibodies had an inhibitory effect on HTR-8/SVneo cell invasion $(P<0.05)$, and a slight but non-significant effect on isolated cytotrophoblast invasion.

Non-immune IgG had no effect on invasion by either cell type.

The influence of IL8 on cell proliferation was assessed by immunocytochemistry for the Ki67 antigen (Fig. 7A). At $5 \mathrm{ng} / \mathrm{ml}$, IL8 increased the proportion of Ki67positive HTR-8/SVneo cells to $146 \%$ of the control value (Fig $7 \mathrm{~B}, P<0.001$ ). Using the $\mathrm{M} 30$ antibody to the caspase-cleaved fragment of cytokeratin-18, the percentage of apoptotic HTR-8/SVneo cells was found to be very low and not altered by treatment with IL8 at $5 \mathrm{ng} / \mathrm{ml}$ (Fig. 7D).

\section{Discussion}

Our results provide evidence that IL8 stimulates the ability of the extravillous CT to migrate and invade through the extracellular matrix in vitro, which is accompanied by increases in MMP2 and MMP9 proform levels and integrins $\alpha_{5}$ and $\beta_{1}$. At the fetal-maternal interface, multiple sources of IL8 have been identified that include CT, syncytiotrophoblast, fetal macrophages, decidual stromal cells, decidual lymphocytes, and endometrial epithelial and gland cells (Saito et al. 1994, Hirota et al. 2009). Among the cells isolated from the decidua, high levels of IL8 were secreted by activated human decidual $\mathrm{CD}^{+}{ }^{+} \mathrm{T}$ lymphocytes (Scaife et al. 2006), and IL8 was produced by CD14 ${ }^{+}$ monocytes (Fest et al. 2007) as well as by decidual NK cells (Hanna et al. 2006). This cytokine modulates multiple biological functions in CXCR1- and CXCR2expressing cells, among which CXCR1 has been detected on invasive trophoblast (Hanna et al. 2006). We present data that both isolated CT and HTR-8/SVneo cells used in functional tests here also express the CXCR1. Cell migration and invasion experiments demonstrated the functionality of the receptors in both cell types. We have tested the hypothesis that IL8 regulates trophoblast migration and invasion in a paracrine and possibly autocrine manner. A range of other chemokine receptors have been found in trophoblast (Hanna et al. 2006, Hannan et al. 2006), and some of their ligands were also shown to promote trophoblast migration (Hannan et al. 2006). Thus, a more complex picture is likely to emerge regarding the role of chemokines in trophoblast migration. Unstimulated HTR-8/SVneo cells have already been shown to produce IL8 at the mRNA and protein levels (Svinarich et al. 1996, Chou et al. 2006), and this was increased by treatment with lipopolysaccharide (Svinarich et al. 1996) and was augmented further by pre-exposure to CRH (Wang et al. 2007). The autocrine action of IL8 was tested by neutralization in HTR-8/SVneo cells. Our data show that blocking endogenous IL8 in unstimulated trophoblast mildly decreased migration in HTR-8/SVneo cells, which is likely to reflect low IL8 levels in unstimulated HTR-8/SVneo cells (Svinarich et al. 1996, Chou et al. 2006).

The stimulation of migration by IL8 shown here for HTR-8/SVneo cells is in keeping with previous results for normal trophoblast in culture (Hanna et al. 2006).

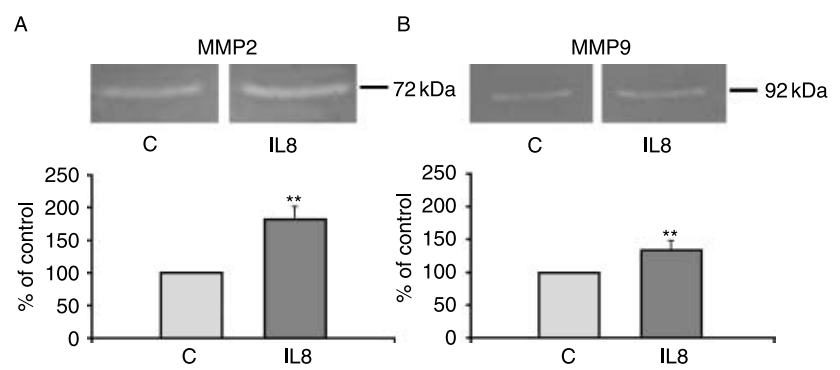

Figure 5 The effect of IL8 $(5 \mathrm{ng} / \mathrm{ml})$ on the MMP2 (A) and MMP9 (B) proform protein levels in HTR-8/SVneo cell culture supernatants in the gelatin zymography assay. Gelatinase levels were semi-quantitated by densitometric analysis of the corresponding bands using the ImageMaster TotalLab v2.01 programme. Data are expressed as the percentage of untreated control with values given as mean \pm S.E.M. (three experiments and two replicates). Statistical significance is given as ** for $P<0.01$. 


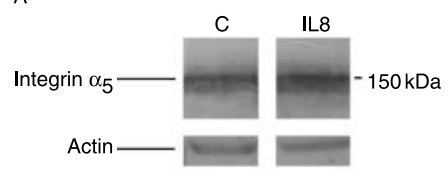

B

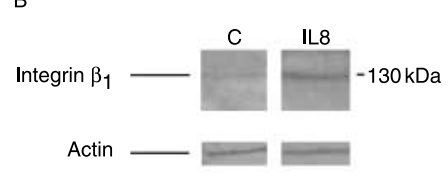

C

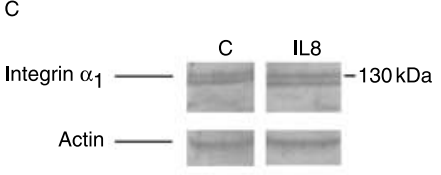

$\alpha_{5}$

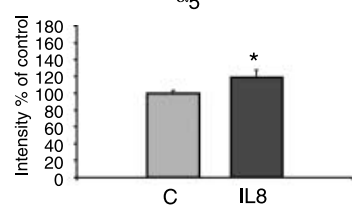

$\beta_{1}$

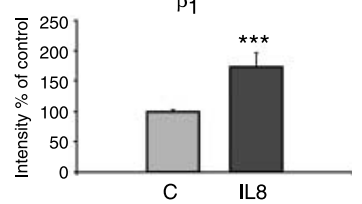

$\alpha_{1}$

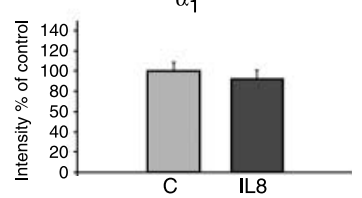

Figure 6 Western blot analysis of integrin $\alpha_{5}, \beta_{1}$, and $\alpha_{1}$ subunit expression in control (C) and IL8-treated ( $5 \mathrm{ng} / \mathrm{ml}) \mathrm{HTR}-8 / \mathrm{SVneo}$ cells. Proteins in cell lysates were resolved by SDS-PAGE on $10 \%$ gel under reducing conditions, and were transferred to nitrocellulose membrane. Membranes with immobilized proteins were probed with anti-integrin $\alpha_{5}(\mathrm{~A})$, anti-integrin $\beta_{1}(\mathrm{~B})$, and anti-integrin $\alpha_{1}(\mathrm{C})$ subunit-specific antibodies. The charts show the densitometric analysis of specific bands using the ImageMaster TotalLab v2.01 programme $(n=6$, from three cultures). Treatment with IL8 $(5 \mathrm{ng} / \mathrm{ml})$ induced significant increases in integrins $\alpha_{5}$ and $\beta_{1}, P<0.05$ and $P<0.001$ respectively, but it had no effect on $\alpha_{1}$ subunit expression. The intensities normalized to actin are expressed as the percentages of untreated control values, and are given as mean \pm s.E.M. Statistical significance is shown as * for $P<0.05$ and $* * *$ for $P<0.01$.

In contrast to the recombinant IL8 used here, Hanna et al. used NK cell supernatant, potentially containing additional active substances, that induced stimulation of migration. We also found enhanced invasion of Matrigel by HTR-8/SVneo cells, and isolated trophoblast exposed to exogenous IL8. In addition, endometrial stromal cells in co-culture with trophoblast were found to up-regulate IL8 most among other genes (Popovici et al. 2006), which suggests the relevance of IL8 for the process of trophoblast invasion. Consistent with our data, IL8 acting in a paracrine fashion qualifies as a factor contributing to permissiveness of the uterine tissues for trophoblast invasion. It has been proposed that IL8 may function as part of the signaling loop between the implanting embryo and the permissive maternal environment, since fetal IL1 stimulated IL8 in endometrial epithelial cells, which in turn was found to stimulate migration and survival of $\mathrm{VCT}$ cells in vitro (Hirota et al. 2009). Decidual NK cell-derived IL8 increased migration/invasion by trophoblast (Hanna et al. 2006). Since endothelial cells also produced IL8 under flow stress (Cheng et al. 2007), IL8 signaling might be relevant for both interstitial and endovascular trophoblast invasion.
It has been suggested that endometrial IL8 can act as a survival factor for trophoblast (Hirota et al. 2009). Our data are supportive of this possibility in the case of the immortalized cell line HTR-8/SVneo, since viable cell numbers were increased upon treatment with IL8. When treated HTR-8/SVneo cells were further analyzed by immunocytochemistry, no effect on apoptosis was observed, but IL8 acted as a proliferation-increasing factor for this EVT cell line. A similar influence of IL8 on

A
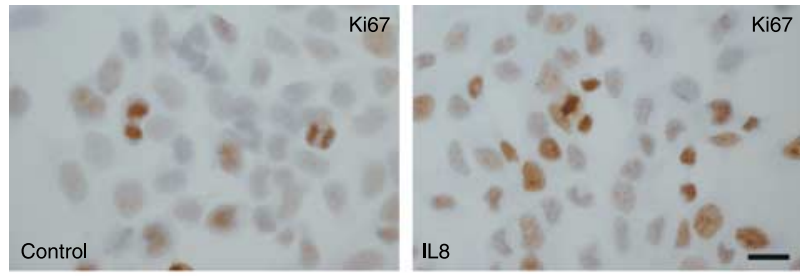

B

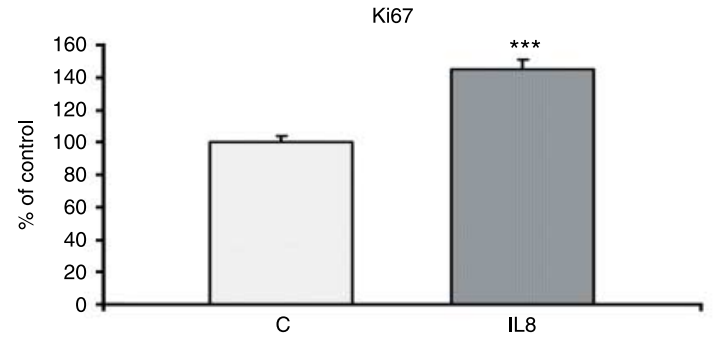

C
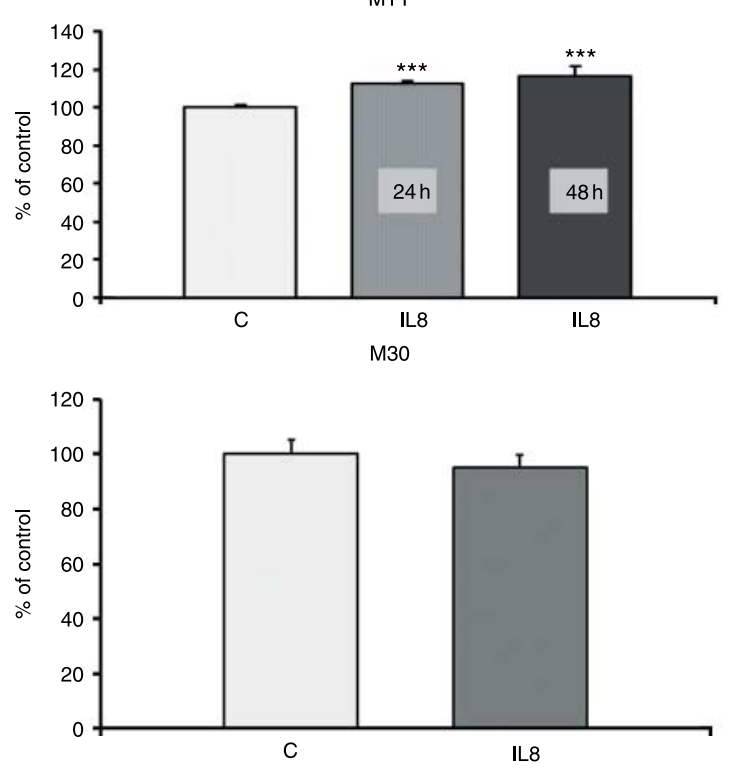

Figure 7 The effect of IL8 on HTR-8/SVneo cell proliferation. Expression of the proliferation marker, Ki67, in control and IL8-treated $(5 \mathrm{ng} / \mathrm{ml}$ ) cell cultures (A). Effects of IL8 on the number of Ki67-positive cells after $72 \mathrm{~h}$ of culture (B, three experiments, 30 fields counted from each, and total $>3000$ cells). The effect of IL8 on viable cell numbers in the MTT test (C, five experiments and 12 replicates in each) and on apoptosis as evidenced by immunostaining for M30 (D, three experiments, 30 fields counted from each, and total $>3000$ cells). Data are expressed as the percentage of untreated control values given as mean \pm S.E.M. Statistical significance is shown as *** for $P<0.001$. Scale bar $=10 \mu \mathrm{m}$. 
cell proliferation was shown for tumor cells, because numbers of proliferating cells were reduced when IL8 was silenced (Merritt et al. 2008). This effect of IL8, however, may not be relevant for non-proliferative EVT.

Cellular invasion requires proteolytic degradation of extracellular matrix molecules. The MMP system is one of the well-documented effector mechanisms important for trophoblast invasion (Librach et al. 1991). The MMPs comprise a large family of enzymes that includes collagenases, stromelysins, and gelatinases, and trophoblast cells are a major source of gelatinases, MMP2 and MMP9 (Cohen et al. 2006). The effect of IL8 on cellular protease levels has not been studied previously in trophoblast cells, but in other systems, effects of IL8 have been shown to depend on MMP activity (Gálvez et al. 2005). Thus, the availability of IL8 for endothelial cells was found to influence proliferation, apoptosis, migration, and production of MMP2 (Li et al. 2003). In cancer models, blocking IL8 induced tumor reduction involving down-regulation of MMP2 and MMP9 activity through modulation of nuclear factor- $\kappa \mathrm{B}$ expression and transcriptional activity (Mian et al. 2003). In pancreatic cancer cell lines, IL8 induced MMP2 and MMP9 activity without increasing proliferation (Kuwada et al. 2003). Other cytokines that affect trophoblast invasiveness have also been found to modulate MMP2 and MMP9 activity, such as IL1 (Librach et al. 1994), IL6 (Meisser et al. 1999), and TGFB (Lash et al. 2005).

It is well established that both the integrin switch in trophoblast differentiation along the extravillous invasive pathway and the activity of specific MMPs are critical for the formation of a fully functional fetal-maternal interface (Damsky et al. 1994). Failure to express adequate integrins has been associated with reduced invasion in vitro (Genbacev et al. 1996) and pathological conditions with impaired trophoblast invasion in vivo, such as preeclampsia (Zhou et al. 1993). As subunits forming fibronectin and laminin/collagen receptors, we studied the integrin proteins $\alpha_{1}, \alpha_{5}$, and $\beta_{1}$ because the involvement of integrins in IL8 stimulation of trophoblast migration has not been investigated so far. Increases in $\alpha_{5}$ and $\beta_{1}$ integrin proteins were found in HTR-8/SVneo cells treated with IL8. Other cytokines and growth factors influencing trophoblast invasion, such as epidermal growth factor or IL6, were also reported to affect integrin expression (Leach et al. 2004, Jovanović \& Vićovac 2009).

It can be concluded that the HTR-8/SVneo cell line expresses functional CXCR1 for IL8, which acts to increase cell migration and invasion, in the manner described for normal EVT. We have shown for the first time that this stimulation is accompanied by increases in pro-MMP2 and pro-MMP9 and integrins $\alpha_{5}$ and $\beta_{1}$. The overall context of IL8-related signaling within the gravid uterus is consistent with the hypothesis that paracrine IL8 contributes to permissiveness of the uterine tissues for trophoblast invasion.

\section{Materials and Methods}

\section{Reagents and antibodies}

RPMI 1640 medium and FCS were obtained from PAA Laboratories (Linz, Austria), Matrigel and collagen type I were obtained from BD Biosciences (Bedford, MA, USA), and IL8 was obtained from R\&D Systems (Oxford, UK). The following antibodies were used: mouse anti-human IL8 with IL8neutralizing activity (clone 6217), anti-IL8 receptor (clone 42 705), anti-integrin $\alpha_{5}$ (R\&D Systems), rabbit anti-integrin $\beta_{1}$ (Chemicon, Temecula, CA, USA), mouse anti-integrin $\alpha_{1}$ (Abcam, Cambridge, UK), mouse anti-Ki67 and mouse antiCK7 (Dako, Glostrup, Denmark), mouse anti-M30 (Roche), mouse anti-cytokeratin-18, and rabbit anti-actin (Sigma). DMEM/F12, trypan blue, gentamycin, antibiotic-antimycotic solution, acrylamide, $N, N^{\prime}$-methylene-bis-acrylamide, $N, N, N^{\prime}, N^{\prime}$-tetramethylenediamine, Ponceau $S$, glycine, protease inhibitor cocktail, and MTT were obtained from Sigma Chemical Company. SDS-PAGE protein standards were obtained from Bio-Rad. Non-immune mouse IgG, biotinylated horse anti-mouse and goat anti-rabbit IgG, avidin-biotinylated peroxidase complex (ABC), and diaminobenzidine (DAB) substrate kit for peroxidase were obtained from Vector Laboratories (Burlingame, CA, USA). Anti-mouse IgG antibody Alexa Fluor 488 and Prolong Gold antifade reagent with DAPI were obtained from Molecular Probes (Invitrogen). Tris and 2-mercaptoethanol were obtained from ICN Biomedicals, Inc. (Aurora, OH, USA). Protran nitrocellulose transfer membrane was obtained from Schleicher \& Schuell BioScience $\mathrm{GmbH}$ Whatman Group (Dassel, Germany). All other reagents were of the best commercial grade available.

Antibody dilutions for immunocytochemistry were 1:6000 for anti-cytokeratin-18, 1:75 for anti-cytokeratin-7, 1:10 for anti-IL8 and anti-IL8R, 1:50 for anti-Ki67, 1:25 for anti-M30, 1:200 for biotinylated horse anti-mouse IgG, and 1:1000 for Alexa Fluor 488 anti-mouse IgG. For western blot analysis, dilutions were 1:100 for anti-integrin $\alpha_{5}, 1: 500$ for anti-integrin $\beta_{1}, 1: 20$ for anti-integrin $\alpha_{1}$ antibody, and 1:2000 for anti-actin. Biotinylated horse anti-mouse and goat anti-rabbit IgG were diluted 1:750 for western blot analysis.

\section{Isolation of CT and cell culture}

HTR-8/SVneo cells were kindly provided by Dr Charles H Graham (Queen's University, Kingston, Ontario, Canada). This cell line was obtained from human first trimester placenta explant cultures immortalized by SV40 large T antigen (Graham et al. 1993, Irving et al. 1995). Primary CT cells were isolated from the first trimester placentas from legal abortions (6-12 weeks) undertaken for non-medical reasons at the Institute of Obstetrics and Gynecology, Clinical Center of Serbia, Belgrade, Serbia, in accordance with the local ethical standards as reported previously (Librach et al. 1991). Briefly, placentas were washed in sterile 0.05 M PBS, pH 7.2 (s-PBS), containing gentamycin and were subjected to two 25-min cycles of digestion with $0.25 \%$ trypsin $(\mathrm{v} / \mathrm{v})$ and $0.2 \mathrm{mg} / \mathrm{ml}$ DNAse I in s-PBS containing $5 \mathrm{mmol} / \mathrm{I} \mathrm{MgCl}_{2}$. Cells released from each step were pooled and filtered through a 40- $\mu$ m nylon sieve (Nylon Bolting Cloth, Lockotex, Warrington, UK), 
resuspended in 20\% Percoll (Pharmacia), and subjected to discontinuous Percoll gradient centrifugation. The trophoblast-containing cell suspension from the middle gradient layer was washed in s-PBS containing $0.1 \%$ BSA $(\mathrm{w} / \mathrm{v})$ and was plated at $1 \times 10^{6} / \mathrm{ml}$ in DMEM/F12, supplemented with $10 \%$ FCS. Cells were identified as trophoblast by immunocytochemical staining for cytokeratin-18 and cytokeratin-7. In all experiments, more than $90 \%$ of the cells were cytokeratin positive. The procedure employed to isolate CT did not involve mincing of placentas, and the cytokeratin18-positive count was in good agreement with that for cytokeratin-7. Since the cell preparations also contained a small percentage of CD45-positive cells $(<6 \%)$, these cells were removed using immunomagnetic beads prior to IL8 receptor evaluation by FACS as described below.

Primary CT was cultured in DMEM/F12 supplemented with $10 \%$ FCS (v/v), and HTR-8/SVneo cells were cultured in RPMI 1640 supplemented with 5\% FCS (v/v) with antibioticantimycotic solution. For SDS-PAGE, HTR-8/SVneo cell lysates were prepared after $24 \mathrm{~h}$ of incubation with or without IL8 $(5 \mathrm{ng} / \mathrm{ml})$. Cells from tissue culture flasks were trypsinized, washed twice in s-PBS, counted, and lysed in a sample buffer containing a protease inhibitor cocktail $\left(6 \times 10^{6}\right.$ cells $\left./ \mathrm{ml}\right)$. Insoluble material was removed by centrifugation $(1600 \mathrm{~g}$ for $5 \mathrm{~min}$ at $4{ }^{\circ} \mathrm{C}$ ). Samples were heated for $5 \mathrm{~min}$ in a boiling water bath.

For immunocytochemical analysis, isolated CT and HTR-8/SVneo cells were cultured on glass cover slips. CT was cultured for $18 \mathrm{~h}$, and HTR-8/SVneo cells were cultured until $\sim 80 \%$ confluence was reached $(72 \mathrm{~h})$ at $37^{\circ} \mathrm{C}$ in a moist atmosphere of air with $5 \% \mathrm{CO}_{2}$. Cover slips were then rinsed twice with s-PBS and were fixed with ice-cold acetone-methanol (1:1) for $10 \mathrm{~min}$. Cover slips were kept frozen until staining.

For the MTT test, HTR-8/SVneo cells were seeded in 96-well plates in $100 \mu \mathrm{l}$ of medium at $2 \times 10^{4}$ cells/well. Cells were allowed to adhere overnight in a humidified chamber with $5 \%$ $\mathrm{CO}_{2}$ at $37^{\circ} \mathrm{C}$. Cells were then carefully rinsed with s-PBS and were challenged with IL8 $(5 \mathrm{ng} / \mathrm{ml})$ dissolved in the medium to a total culture volume of $200 \mu \mathrm{l}$. After $24 \mathrm{~h}$, the cells were carefully rinsed twice with warm s-PBS.

For gelatin zymography, $1 \times 10^{5} \mathrm{HTR}-8 / \mathrm{SV}$ neo cells were seeded in $300 \mu \mathrm{l} \mathrm{RPMI} 1640$ with $5 \%$ FCS $(\mathrm{v} / \mathrm{v})$ per well in 24-well plates. Cells were incubated at $37^{\circ} \mathrm{C}$ in a moist atmosphere of air with $5 \% \mathrm{CO}_{2}$ until close to confluence. They were then carefully rinsed twice with warm s-PBS, and $200 \mu \mathrm{l}$ of serum-free RPMI 1640 without or with IL8 (5 ng/ml) were added. Cells were incubated for another $24 \mathrm{~h}$. Culture media were then collected and centrifuged for $5 \mathrm{~min}$ at $700 \mathrm{~g}$ to remove any cells, and the protein concentrations were determined using the BCA assay (Pierce Biotechnology, Rockford, IL, USA).

\section{Immunocytochemistry}

Cell cultures were washed with PBS, air-dried, and fixed with ice-cold acetone-methanol. Non-specific binding was blocked for endogenous peroxidase activity with $1 \%$ hydrogen peroxide for $30 \mathrm{~min}$, and non-specific binding of proteins was blocked with $1 \%$ casein in PBS for $20 \mathrm{~min}$ at room temperature (RT). The cells were then incubated with the primary anti-cytokeratin-18 antibody for $1 \mathrm{~h}$ at RT. This was followed by incubation with biotinylated horse anti-mouse IgG secondary antibody for $30 \mathrm{~min}$ and with $\mathrm{ABC}$ for another 30 min. Between steps, cells were washed with PBS. Reaction was visualized using DAB as the chromogen. Negative controls were performed routinely. Omission of the primary antibody and use of non-immune serum in place of specific antibody resulted in the complete absence of staining. Slides were then mounted and examined using a Reichert-Jung microscope with Leica DC150 Digital Camera System (Wetzlar, Germany). Cell purity of the isolated trophoblast determined by immunostaining with cytokeratin-18 was $>90 \%$.

HTR-8/SVneo cells were stained for Ki67 antigen as a marker of cell proliferation and for M30 as a marker of cell apoptosis using the procedure described above. Reaction was visualized using DAB as the chromogen. The nuclei were visualized by hematoxylin staining. Slides were then mounted and examined using a Reichert-Jung microscope with Leica DC150 Digital Camera System. Ki67- and M30-positive cells were counted on cover slips from three different experiments.

Isolated CT and HTR-8/SVneo cells on cover slips were stained using mouse anti-hIL8 and anti-hIL8R antibody and anti-mouse IgG antibody Alexa Fluor 488. Cells were first stained for CK-18 using biotinylated anti-mouse IgG antibodies followed by $A B C$ with $\mathrm{DAB}$ as the chromogen to confirm its identity as described above. The cells were then extensively rinsed with PBS and blocked for non-specific binding with $1 \%$ casein in PBS (w/v) for $20 \mathrm{~min}$. They were incubated with anti-hIL8 and anti-hIL8R antibodies overnight at $4{ }^{\circ} \mathrm{C}$, and then with anti-mouse IgG antibody Alexa Fluor 488 for $30 \mathrm{~min}$. Slides were mounted with Prolong Gold antifade reagent with DAPI and examined using a Carl Zeiss Axio Imager 1.0 microscope (Jena, Germany), with a Canon A640 Digital Camera System (Tokyo, Japan).

\section{Flow cytometry}

Flow cytometry was used to evaluate the expression of CXCR1 on HTR-8/SVneo and isolated trophoblast cells. Magnetic beads coated with antibody to CD45 were used to deplete bone marrow-derived cells from the isolated CT cell suspension. Dynabeads - M-280 sheep anti-mouse IgG (Invitrogen) were coated with mouse anti-CD45 MAB (1:100; Serotec, Oxford, UK) according to the manufacturer's instructions. The coated beads were stored in PBS/ $0.1 \%$ BSA at $4{ }^{\circ} \mathrm{C}$ until use. Isolated cell suspensions were incubated with coated beads for $1 \mathrm{~h}$ at $4{ }^{\circ} \mathrm{C}$ with rotation. Beads with attached CD45-positive cells were removed magnetically. The resulting $\mathrm{CT}$ cells were washed four times with $\mathrm{PBS} / 0.1 \% \mathrm{BSA}$, and the purity was estimated by cytospins stained with anti-CD45 and anti-CK7 antibodies. The purity of the stained cells was $>98 \%$. Purified CT cells $\left(8 \times 10^{5}\right.$ cells/tube) or HTR-8/SVneo cells $\left(8 \times 10^{5}\right.$ cells/tube) were washed twice with cold $\mathrm{PBS}_{2}$ (PBS, $2 \%$ FCS, and $0.01 \%$ sodium azide), and were permeabilized with fixation/permeabilization concentrate diluted in fixation/ permeabilization diluent, 1:4 (eBioscience, San Diego, CA, USA), overnight at $4{ }^{\circ} \mathrm{C}$. Cells were washed twice in permeabilization buffer $(\mathrm{PB})$, diluted in deionized water (1:10), 
and incubated with anti-CXCR1 antibody for $45 \mathrm{~min}$ at $4{ }^{\circ} \mathrm{C}$. After incubation and subsequent washing with $\mathrm{PB}$, cells were stained for 30 min with Alexa Flour 488 goat anti-mouse IgG diluted 1:1000 in PB with 5\% goat serum. Control cells were incubated with non-immune mouse $\lg G$ as the primary antibody. Labeled cells were fixed with $4 \%$ formalin, and were analyzed on an EPICS XL-MCL flow cytometer (Coulter, Krefeld, Germany).

\section{Cell wounding and migration assay}

The effect of IL8 and anti-IL8 antibodies on HTR-8/SVneo cell migration was investigated as follows: $5 \times 10^{5} \mathrm{HTR}-8 / \mathrm{SV}$ neo cells were plated in 6 -well plates in $2 \mathrm{ml}$ of medium and incubated at $37{ }^{\circ} \mathrm{C}$ in $5 \% \mathrm{CO}_{2}$ until confluence. Cells were then scraped off with a sterile pipette tip and rinsed with s-PBS twice. Medium (2 ml) without or with IL8 at 0.5, 1, 5, and $10 \mathrm{ng} / \mathrm{ml}$ and without or with function-blocking anti-IL8 or non-immune IgG at $1 \mu \mathrm{g} / \mathrm{ml}$ was then added. The pre-selected fields were photographed at 0 point after 3 and $24 \mathrm{~h}$. The width of the denuded area was measured using an electronic grid, and the distances crossed by the cells were determined. The mean of the controls was set to $100 \%$, and the data are expressed as the percentage of the control values. The experiment was repeated four times in duplicate.

\section{Cell invasion assay}

Transwell invasion assays were conducted in 24 well-fitted wells with membranes (polyethylene terephthalate, tracketched membrane of $6.4 \mathrm{~mm}$ diameter, with $8 \mu \mathrm{m}$ porosity, Falcon, BD Labware, Franklin Lakes, NJ, USA) as described previously (Librach et al. 1991) with minor modifications. Briefly, primary CT cells $\left(2 \times 10^{5}\right)$ and HTR-8/SVneo cells $\left(1 \times 10^{5}\right)$ were resuspended in the medium with or without IL8 (1 and $5 \mathrm{ng} / \mathrm{ml}$ ), function-blocking anti-IL8 antibodies, or nonimmune $\lg G(1 \mu \mathrm{g} / \mathrm{ml})$. Cells were then seeded in the upper chamber of Matrigel-coated transwells. Insert membranes were previously coated on the upper side with $10 \mu$ of growth factorreduced Matrigel at $5 \mathrm{mg} / \mathrm{ml}$ by incubation for $30 \mathrm{~min}$ at $37^{\circ} \mathrm{C}$. The lower chambers were loaded with $500 \mu$ of medium with or without IL8, anti-IL8, or non-immune IgG antibodies. Cells were incubated for $24 \mathrm{~h}$ at $37^{\circ} \mathrm{C}$ in $5 \% \mathrm{CO}_{2}$. The chamber was disassembled, filters were washed twice in warm PBS, and cells on the upper surface were gently removed with a cotton swab. Cells were fixed in 4\% paraformaldehyde with $0.05 \%$ Tween $(\mathrm{v} / \mathrm{v})$ for $30 \mathrm{~min}$ at RT. Filters were stained using primary anticytokeratin-18 for primary trophoblast by the same procedure as described above, and by Giemsa staining for HTR-8/SVneo cells. Cells on the underside of the filters and the pores occupied were counted in 40 randomly selected non-overlapping fields of the membranes under a light microscope (Reichert-Jung with Leica DC150 Digital Camera System). The mean of the controls was set to $100 \%$, and the data are expressed as the percentage of the control values. Experiments were performed four times in duplicate for isolated trophoblast and six times in duplicate for HTR-8/SVneo cells. Data presented for HTR-8/SVneo were normalized to cell numbers (increased by IL8 as assessed by the MTT test). In the Matrigel invasion test, isolated CT differentiates to non-proliferative trophoblast.

\section{Determination of viable cell number}

The MTT test was used as an indicator of cell number (Hanisch et al. 1993). HTR-8/SVneo cells were cultured in 96-well plates as described above. At the end of the incubation interval, $100 \mu \mathrm{l}$ of MTT $(2.4 \mathrm{mmol} / \mathrm{l})$ in $10 \% \mathrm{FCS} / \mathrm{PBS}(\mathrm{v} / \mathrm{v})$ were added to each well. After incubation for $2 \mathrm{~h}$ at $37^{\circ} \mathrm{C}$, medium was replaced by 1 -propanol $(100 \mu \mathrm{l} /$ well $)$, and the plates were vigorously shaken to ensure complete solubilization of the blue formazan. Absorbance was measured at $570 \mathrm{~nm}$ using a microplate reader (LKB), and cell numbers were determined using a standard curve obtained with $5 \times 10^{3}, 1 \times 10^{4}, 2 \times 10^{4}$, $4 \times 10^{4}, 6 \times 10^{4}$, or $8 \times 10^{4}$ cells/well. The experiment was repeated five times, $n=12$.

\section{Gelatin zymography}

HTR-8/SVneo cells were incubated as described above. Gelatinase activities in serum-free conditioned media of HTR8/SVneo cells were determined using SDS-polyacrylamide gel zymography as described previously (Lash et al. 2005). Samples were electrophoresed on $11 \%$ SDS-polyacrylamide gels containing $1 \mathrm{mg} / \mathrm{ml}$ of gelatin under non-reducing conditions. All samples for comparison were run on the same gel, with $25 \mu \mathrm{g}$ of protein loaded per lane. Following electrophoresis, gels were washed twice for $15 \mathrm{~min}$ in $2.5 \%$ Triton X-100 (v/v) to remove SDS, and were then rinsed in $\mathrm{dH}_{2} \mathrm{O}$. After overnight incubation in reaction buffer $(50 \mathrm{mmol} / \mathrm{l}$ Tris- $\mathrm{HCl}, \mathrm{pH} 7$, containing $5 \mathrm{mmol} / \mathrm{I} \mathrm{CaCl}_{2}$ ) at $37^{\circ} \mathrm{C}$, gels were stained with Coomassie brilliant blue R-250 for $30 \mathrm{~min}$ at RT and were destained in $30 \%$ methanol and $10 \%$ glacial acetic acid (v/v). Proteinase activity was observed as a clear band of digested gelatin. Gelatinase levels were semi-quantitated by densitometric analysis of zymograms using the ImageMaster TotalLab v2.01 programme (Amersham Biosciences). All zymography experiments were repeated at least three times in duplicate.

\section{SDS-PAGE and immunoblotting}

SDS-PAGE was performed on $10 \%$ polyacrylamide gel and $4 \%$ stacking gel under reducing conditions. All samples (HTR-8/SVneo cell lysates) were prepared by boiling in $0.125 \mathrm{M}$ Tris-HCl buffer containing 4\% SDS (w/v), 20\% glycerol $(\mathrm{v} / \mathrm{v}), 0.1 \%$ bromophenol blue, and 10\% 2-mercaptoethanol $(\mathrm{v} / \mathrm{v})$ for $5 \mathrm{~min}$, and $80 \mu \mathrm{g}$ of protein were loaded per lane. SDS-PAGE standards (Bio-Rad) were used as molecular weight markers. Proteins separated by electrophoresis were transferred onto nitrocellulose membranes. Transfer was performed at constant power $\left(1.2 \mathrm{~mA} / \mathrm{cm}^{2}\right)$ for $1.5 \mathrm{~h}$, and was confirmed by Ponceau $\mathrm{S}$ staining of the membranes. Non-specific binding was blocked with $1 \%$ casein in PBS (w/v) overnight at $4{ }^{\circ} \mathrm{C}$. After blocking, membranes with immobilized antigens were incubated with monoclonal anti-integrin $\alpha_{1}, \alpha_{5}$, or $\beta_{1}$ antibody overnight at $4{ }^{\circ} \mathrm{C}$ with constant shaking. After five washes for 5 min each, membranes were incubated with the anti-mouse IgG biotinylated secondary antibody for $30 \mathrm{~min}$. After intensive washing, membranes were incubated with $A B C$ for 30 min. Bound conjugates were visualized using $\mathrm{DAB} / \mathrm{Ni}$ as the chromogen. Non-specific binding was estimated by omitting 
the specific antibody. Staining for actin was used as the loading control. Membranes $(n=3)$ were examined on a HP Scanjet G3110 scanner, and were analyzed by the ImageMaster TotalLab v2.01 programme (Amersham Biosciences).

\section{Statistical analysis}

The data were analyzed statistically with the Statistical Software Program, version 5.0 (Primer of Biostatistic, McGraw-Hill Companies, Inc., New York, NY, USA) using the non-parametric Mann-Whitney rank sum test and Student's $t$-test as appropriate. Values were considered significantly different when $P<0.05$.

\section{Declaration of interest}

The authors declare that there is no conflict of interest that could affect the impartiality of the research reported.

\section{Funding}

This work was supported by project 143059 of the Ministry of Science and Technological Development, Republic of Serbia.

\section{Acknowledgements}

The authors thank Dr Charles Graham for sharing the HTR-8/SVneo cell line.

\section{References}

Arici A, Head JR, MacDonald PC \& Casey ML 1993 Regulation of interleukin-8 gene expression in human endometrial cells in culture. Molecular and Cellular Endocrinology 94 195-204.

Bauer S, Pollheimer J, Hartmann J, Husslein P, Aplin JD \& Knofler M 2004 Tumor necrosis factor-alpha inhibits trophoblast migration through elevation of plasminogen activator inhibitor-1 in first-trimester villous explant cultures. Clinics in Endocrinology and Metabolism 89 812-822.

Caniggia I, Grisaru-Gravnosky S, Kuliszewsky M, Post M \& Lye SJ 1999 Inhibition of TGF-beta 3 restores the invasive capability of extravillous trophoblasts in preeclamptic pregnancies. Journal of Clinical Investigation 103 1641-1650.

Cheng M, Wu J, Liu X, Li Y, Nie Y, Li L \& Chen H 2007 Low shear stressinduced interleukin-8 mRNA expression in endothelial cells is mechanotransduced by integrins and the cytoskeleton. Endothelium 14 265-273.

Chou D, Ma Y, Zhang J, McGrath C \& Parry S 2006 Cytomegalovirus infection of trophoblast cells elicits an inflammatory response: a possible mechanism of placental dysfunction. American Journal of Obstetrics and Gynecology 194 535-541.

Cohen M, Meisser A \& Bischof P 2006 Metalloproteinases and human placental invasiveness. Placenta 27 783-793.

Damsky CH, Fitzgerald ML \& Fisher SJ 1992 Distribution patterns of extracellular matrix components and adhesion receptors are intricately modulated during first trimester cytotrophoblast differentiation along the invasive pathway in vivo. Journal of Clinical Investigation 89 210-222.

Damsky CH, Librach C, Lim KH, Fitzgerald ML, McMaster MT, Janatpour M, Zhou Y, Logan SK \& Fisher SJ 1994 Integrin switching regulates normal trophoblast invasion. Development 120 3657-3666.
Fest S, Aldo PB, Abrahams VM, Visintin I, Alvero A, Chen R, Chavez SL, Romero R \& Mor G 2007 Trophoblast-macrophage interactions: a regulatory network for the protection of pregnancy. American Journal of Reproductive Immunology 57 55-66.

Fisher SJ, Leitch MS, Kantor MS, Basbaum CB \& Kramer RH 1985 Degradation of extracellular matrix by the trophoblastic cells of firsttrimester human placentas. Journal of Cellular Biochemistry 27 31-41.

Gálvez BG, Genís L, Matías-Román S, Oblander SA, Tryggvason K, Apte SS \& Arroyo AG 2005 Membrane type 1-matrix metalloproteinase is regulated by chemokines monocyte-chemoattractant protein-1/ccl2 and interleukin-8/CXCL8 in endothelial cells during angiogenesis. Journal of Biological Chemistry 280 1292-1298.

Genbacev O, Joslin R, Damsky CH, Polliotti BM \& Fisher SJ 1996 Hypoxia alters early gestation human cytotrophoblast differentiation/invasion in vitro and models the placental defects that occur in preeclampsia. Journal of Clinical Investigation 97 540-550.

Graham CH, Hawley TS, Hawley RC, MacDougall JR, Kerbel RS, Khoo N \& Lala PK 1993 Establishment and characterization of first trimester human trophoblast cells with extended lifespan. Experimental Cell Research 206 204-211.

Hanisch FG, Dressen F \& Uhlenbruck G 1993 Quantitative micro-adhesion assay on polystyrene matrices. In Lectins and Glycobiology, pp 411-417. Eds HJ Gabius \& S Gabius. Berlin, Heidelberg: Springer-Verlag.

Hanna J, Goldman-Wohl D, Hamani Y, Avraham I, Greenfield C, Natanson-Yaron S, Prus D, Cohen-Daniel L, Arnon TI, Manaster I et al. 2006 Decidual NK cells regulate key developmental processes at the human fetal-maternal interface. Nature Medicine 12 1065-1074.

Hannan NJ, Jones RL, White CA \& Salamonsen LA 2006 The chemokines, CX3CL1, CCL14, and CCL4, promote human trophoblast migration at the feto-maternal interface. Biology of Reproduction 74 896-904.

Harada A, Sekido N, Akahoshi T, Wada T, Mukaida N \& Matsushima K 1994 Essential involvement of interleukin-8 (IL-8) in acute inflammation. Journal of Leukocyte Biology 56 559-564.

Hirota Y, Osuga Y, Hasegawa A, Kodama A, Tajima T, Hamasaki K, Koga K, Yoshino O, Hirata T, Harada M et al. 2009 Interleukin (IL)-1beta stimulates migration and survival of first-trimester villous cytotrophoblast cells through endometrial epithelial cell-derived IL-8. Endocrinology 150 350-356.

Huber AR, Kunkel SL, Todd RF III \& Weiss SJ 1991 Regulation of transendothelial neutrophil migration by endogenous interleukin-8. Science 254 99-102.

lizasa H \& Matsushima K 2000 IL-8/CXCL8. In Cytokine Reference, vol 1, 2nd edn, pp 1062. Eds JJ Oppenheim, M Feldmann, SK Durum, T Hirano, J Vilcek \& NA Nicola. San Diego: Academic Press.

Irving JA, Lysiak JJ, Graham CH, Hearn S, Han VK \& Lala PK 1995 Characteristics of trophoblast cells migrating from first trimester chorionic villus explants and propagated in culture. Placenta $\mathbf{1 6}$ 413-433.

Jovanović M \& Vićovac L 2009 Interleukin-6 stimulates cell migration, invasion and integrin expression in HTR-8/SVneo cell line. Placenta $\mathbf{3 0}$ 320-328.

Koch AE, Polverini PJ, Kunkel SL, Harlow LA, DiPietro LA, Elner VM, Elner SG \& Strieter RM 1992 Interleukin-8 as a macrophage-derived mediator of angiogenesis. Science 258 1798-1801.

Kuwada Y, Sasaki T, Morinaka K, Kitadai Y, Mukaida N \& Chayama K 2003 Potential involvement of IL-8 and its receptors in the invasiveness of pancreatic cancer cells. International Journal of Oncology 22 765-771.

Lala PK \& Graham CH 1990 Mechanisms of trophoblast invasiveness and their control: the role of proteases and protease inhibitors. Cancer and Metastasis Reviews 9 369-379.

Lash GE, Otun HA, Innes BA, Bulmer JN, Searle RF \& Robson SC 2005 Inhibition of trophoblast cell invasion by TGFB1, 2, and 3 is associated with a decrease in active proteases. Biology of Reproduction 73 374-381.

Lash GE, Otun HA, Innes BA, Kirkley M, De Oliveira L, Searle RF, Robson SC \& Bulmer JN 2006 Interferon-gamma inhibits extravillous trophoblast cell invasion by a mechanism that involves both changes in apoptosis and protease levels. FASEB Journal 20 2512-2518.

Leach RE, Kilburn BA, Wang J, Liu Z, Romero R \& Armant DR 2004 Heparin binding EGF-like growth factor regulates human extravillous cytotrophoblast development during conversion to the invasive phenotype. Developmental Biology 266 223-237. 
Li A, Dubey S, Varney ML, Dave BJ \& Singh RK 2003 IL-8 directly enhanced endothelial cell survival, proliferation, and matrix metalloproteinases production and regulated angiogenesis. Journal of Immunology $\mathbf{1 7 0}$ 3369-3376.

Librach CL, Werb Z, Fitzgerald ML, Chiu K, Corwin NM, Esteves RA, Grobelny D, Galardy R, Damsky CH \& Fisher SJ 1991 92-kD type IV collagenase mediates invasion of human cytotrophoblasts. Journal of Cell Biology 113 437-449.

Librach CL, Feigenbaum SL, Bass KE, Cui TY, Verastas N, Sadovsky Y, Quigley JP, French DL \& Fisher SJ 1994 Interleukin-1 beta regulates human cytotrophoblast metalloproteinase activity and invasion in vitro. Journal of Biological Chemistry 269 17125-17131.

Meisser A, Cameo P, Islami D, Campana A \& Bischof P 1999 Effects of interleukin-6 (IL-6) on cytotrophoblastic cells. Molecular Human Reproduction 5 1055-1058.

Merritt WM, Lin YG, Spannuth WA, Fletcher MS, Kamat AA, Han LY, Landen CN, Jennings N, De Geest K, Langley RR et al. 2008 Effect of interleukin-8 gene silencing with liposome-encapsulated small interfering RNA on ovarian cancer cell growth. Journal of the National Cancer Institute 100 359-372.

Mian BM, Dinney CP, Bermejo CE, Sweeney P, Tellez C, Yang XD, Gudas JM, McConkey DJ \& Bar-Eli M 2003 Fully human anti-interleukin 8 antibody inhibits tumor growth in orthotopic bladder cancer xenografts via down-regulation of matrix metalloproteases and nuclear factorkappaB. Clinical Cancer Research 9 3167-3175.

Pijnenborg R, Bland JM, Robertson WB \& Brosens I 1983 Uteroplacental arterial changes related to interstitial trophoblast migration in early human pregnancy. Placenta 4 397-413.

Poehlmann TG, Fitzgerald JS, Meissner A, Wengenmayer T, Schleussner E, Friedrich K \& Markert UR 2005 Trophoblast invasion: tuning through LIF, signalling via Stat3. Placenta 26 S37-S41.

Popovici RM, Betzler NK, Krause MS, Luo M, Jauckus J, Germeyer A, Bloethner S, Schlotterer A, Kumar R, Strowitzki T et al. 2006 Gene expression profiling of human endometrial-trophoblast interaction in a coculture model. Endocrinology 147 5662-5675.

Saito S, Kasahara T, Sakakura S, Umekage H, Harada N \& Ichijo M 1994 Detection and localization of interleukin-8 mRNA and protein in human placentaand decidual tissues. Journal of Reproductive Immunology 27 161-172.
Salamonsen LA, Hannan NJ \& Dimitriadis E 2007 Cytokines and chemokines during human embryo implantation: roles in implantation and early placentation. Seminars in Reproductive Medicine 25 437-444.

Sanchez X, Suetomi K, Cousins-Hodges B, Horton JK \& Navarro J 1998 CXC chemokines suppress proliferation of myeloid progenitor cells by activationof the CXC chemokine receptor 2. Journal of Immunology $\mathbf{1 6 0}$ 906-910.

Scaife PJ, Bulmer JN, Robson SC, Innes BA \& Searle RF 2006 Effector activity of decidual $\mathrm{CD}^{+} \mathrm{T}$ lymphocytes in early human pregnancy. Biology of Reproduction 75 562-567.

Shimoya K, Matsuzaki N, Taniguchi T, Kameda T, Koyama M, Neki R, Saji F \& Tanizawa O 1992 Human placenta constitutively produces interleukin-8 during pregnancy and enhances its production in intrauterine infection. Biology of Reproduction 47 220-226.

Starkey PM, Sargent IL \& Redman CW 1988 Cell populations in human early pregnancy decidua: characterization and isolation of large granular lymphocytes by flow cytometry. Immunology 65 129-134.

Svinarich DM, Bitonti OM, Romero R \& Gonik B 1996 Induction and posttranslational expression of cytokines in a first-trimester trophoblast cell line by lipopolysaccharide. American Journal of Obstetrics and Gynecology 175 970-973.

Tsui KH, Chen LY, Shieh ML, Chang SP, Yuan CC \& Li HY 2004 Interleukin8 can stimulate progesterone secretion from a human trophoblast cell line, BeWo. In Vitro Cellular \& Developmental Biology. Animal 40 331-336.

Wang W, Nan X, Ji P \& Dow KE 2007 Corticotropin releasing hormone modulates endotoxin-induced inflammatory cytokine expression in human trophoblast cells. Placenta 28 1032-1038.

Zhou Y, Damsky CH, Chiu K, Roberts JM \& Fisher SJ 1993 Preeclampsia is associated with abnormal expression of adhesion molecules by invasive cytotrophoblasts. Journal of Clinical Investigation 91 950-960.

Received 11 August 2009

First decision 22 September 2009

Revised manuscript received 22 January 2010

Accepted 4 February 2010 